\title{
Erratum to: Bone Marrow Derived Pluripotent Cells are Pericytes which Contribute to Vascularization
}

\author{
Xiaoxiao Cai • Yunfeng Lin • Claudia C. Friedrich • Craig Neville • \\ Irina Pomerantseva $\cdot$ Cathryn A. Sundback - Zhiyuan Zhang • Joseph P. Vacanti • \\ Peter V. Hauschka • Brian E. Grottkau
}

Published online: 20 November 2009

(C) Humana Press 2009

\section{Erratum to: Stem Cell Rev and Rep \\ DOI 10.1007/s12015-009-9097-6}

Please note the following errors in the original version.

\section{Page 1, Authorship and Study Location:}

1. Dr. Parul Sharma was not an author of this paper.

2. The footnote stating the location of the study declined to list the Department of Orthopaedic Surgery, Children's Hospital Boston, Harvard Medical School, Boston MA in addition to the Pediatric Orthopaedic Laboratory for Tissue Engineering, Mass General Hospital for Children.

The online version of the original article can be found at http://dx.doi. org/10.1007/s12015-009-9097-6.

X. Cai $\cdot$ Y. Lin $(\bowtie)$

State Key Laboratory of Oral Diseases,

West China College of Stomatology, Sichuan University,

Chengdu 610041, People's Republic of China

e-mail: yunfenglin@scu.edu.cn

X. Cai $\cdot$ Z. Zhang $\cdot$ P. V. Hauschka

Department of Orthopaedic Surgery, Children's Hospital Boston, Harvard Medical School,

Boston, MA, USA

Y. Lin $\cdot$ C. C. Friedrich $\cdot$ C. Neville $\cdot$ I. Pomerantseva $\cdot$

C. A. Sundback $\cdot$ J. P. Vacanti

Center for Regenerative Medicine,

Massachusetts General Hospital, Harvard Medical School,

Boston, MA 02114, USA

Y. Lin · B. E. Grottkau ( $\bowtie)$

Department of Orthopaedic Surgery, Mass General Hospital for

Children and the Pediatric Orthopaedic Laboratory for Tissue

Engineering, Harvard Medical School,

Boston, MA, USA

email: bgrottkau@partners.org

\section{Abstract:}

3. There is a typographical error in the second sentence of the abstract. Where is written "maker" should be read "marker."

4. In the last sentence of the Abstract, where is written "...the bone marrow derived pluripotent cells are pericytes and can contribute to vascularization" should read "the bone marrow derived pluripotent cells include pericytes and can contribute to vascularization."

Materials and Methods:

5. On page 2, under the subheading "Experimental Mouse Model," where is written "The transgenic mice were provided by..." should read, "The transgenic mice originally developed by Jen-Yue Tsai (NEI/NIH) [15] were obtained through the courtesy of John D. Ash and Sanai Sato (University of Oklahoma Health Science Center). The strain was rederived and characterized (unpublished data) by Parul Sharma in..."

6. On page 2, the sub-section labeled "Isolation of Bone Marrow Stromal Cells from $\alpha$-SMA-GFP Transgenic Mouse" in its entirety should read "Bone marrow stem cells were collected from 8 -week-old male $\alpha$-SMAGFP transgenic mice weighing 20 25 g, as previously described [16]. Briefly, mice were sacrificed by $\mathrm{CO}_{2}$ inhalation. The complete tibia and femurs were obtained and both ends of the metaphysic were removed. Sterile serum-free medium was slowly injected into the bone marrow cavity to collect the bone marrow stromal cells. Bone marrow stromal cells were cultured in alpha-MEM containing $10 \%$ fetal bovine serum + ribonucleosides and maintained in a humidified atmosphere of $5 \% \mathrm{CO}_{2}$ at $37^{\circ} \mathrm{C}$." 
7. On page 2, in the third sentence under "Histochemical Staining," where is written "The cells were differentiated..." should read "The cells were rinsed..."

8. On page 3 , in the second sentence, where is written "( $\mathrm{pH} 4.2)$ " should read "(in 1\% KOH)".

Results:

9. On page 3, the first sentence under "Morphological Features and Proliferation Characters of $\alpha$-SMA-GFP Positive Cells and HUVECs" should read: "Approximately $1 \times 10^{6}$ cells were obtained from the bone marrow of each $\alpha$-SMA-GFP transgenic mouse."

10. On page 4, in the second paragraph, the second sentence should read "According to the FACS results: flushed bone marrow initially contains $0.05-0.5 \% \alpha$-SMA-GFP positive cells. In the primary passage (passage 0 ) of bone marrow stromal cells, the $\alpha$-SMA-GFP positive cells represented $17 \pm 3.45 \%$ after trypsinization; in passage 1 , the percentage was $32 \pm 5.85 \%$; in passage 2 , the percentage was $58 \pm 8.61 \%$; and in the passage 3 , the percentage was $89 \pm 7.53 \%$ (Figure $2 \mathrm{~A}$ )."

Acknowledgements:

11. On page 9, the Acknowledgements should instead read as follows: "This work was funded by the Anthony and Constance Franchi Fund for Pediatric Orthopaedics at the MassGeneral Hospital for Children, The Peabody Foundation Inc., the National Natural Science Foundation of China (30801304), the Department of Defense/CDMRP Breast Cancer Research Program under grants managed by the U.S. Army Materiel and Research Command (W81XWH-09-1-0292, and W81XWH03-1-0607) (PVH), and research funds from the Department of Orthopaedic Surgery, Children's Hospital Boston." 